\title{
MUSCLE TRANSPLANTATION AFTER A COMPLETE SEVERANCE OF THE MEDIAL RECTUS MUSCLE*
}

\author{
BY \\ OEY-KHOEN LIAN \\ Semarang, Indonesia
}

MARINA (1912, 1915) found, after transplanting the ocular muscles in monkeys, an immediate restoration of normally co-ordinated eye-movements, a phenomenon which he ascribed to the absence of any fixed and predetermined function in the nuclei and association tracts of the central nervous system (Duke-Elder, 1949). The following case confirms Marina's statements.

\section{Case Report}

An Indonesian woman aged 25 years, stumbled so that her right eye came in contact with the hooked handle of a frying-slice (Fig. 1) which was resting at an angle in the utensil rack on the wall. As she stood up again, the slice was dangling from her right eye, the hook having penetrated the bulbar conjunctiva. A "helpful" member of the family pulled the hook out, and after this the patient experienced diplopia.

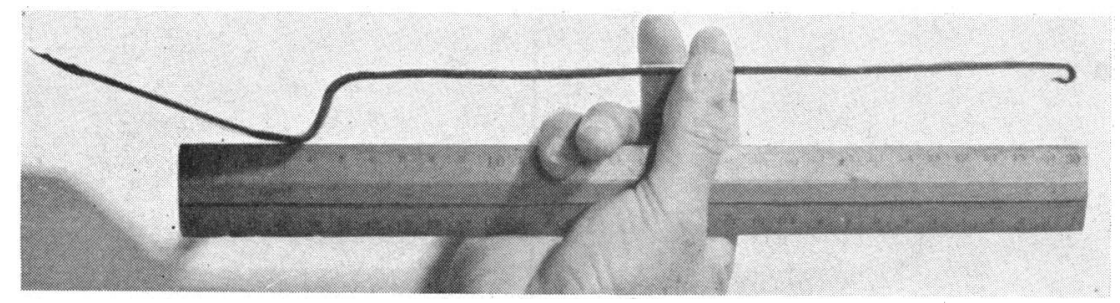

FIG. 1.-Frying slice, showing length and hooked handle.

The accident happened at about 7 a.m. on August 13, 1959, and when she was admitted to hospital at 11 a.m. the medial rectus muscle of the right eye was found to be paralysed (Fig. 2). The ocular motility in other directions was good. The pupil was rather enlarged, but the visual acuity was normal. At 5.15 p.m., under 2 per cent. procaine anaesthesia without adrenalin, an exploration was performed and it was found that the right medial rectus muscle was completely severed at a point $2 \mathrm{~mm}$. from its insertion. As it was not possible to find the other end of the muscle without damaging the surrounding tissues too much, I decided to transpose half of the superior rectus and half of the inferior rectus to the stump of the injured medial rectus. The tonus of the lateral rectus was first weakened by tenotomy.

Figs 3 and 4 show the ocular movements 1 hour after the operation, when no movement was noticeable looking to the left (Fig. 4). However, 2 hours after the operation (Fig. 5), it was clear that there was adduction in the right eye. 


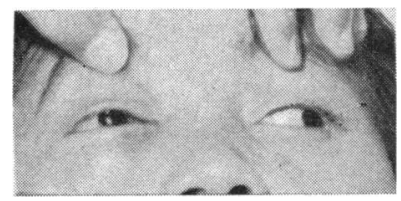

FIG. 2.-Before treatment, looking to the left.

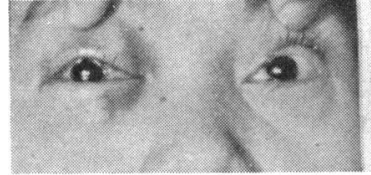

FIG. 3.-One hour after operation, looking straight ahead.

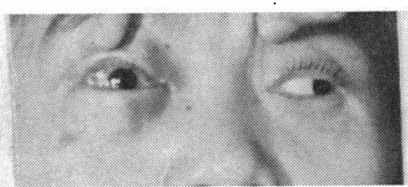

Fig. 4.- One hour after operation, looking to the left.

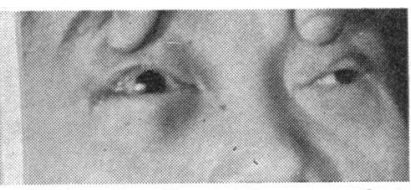

FIG. 5.-Two hours after operation, looking to the left.

Figs $6,7,8,9$, and 10 show the condition 48 days after the operation, and Fig. 11 8 months later still.
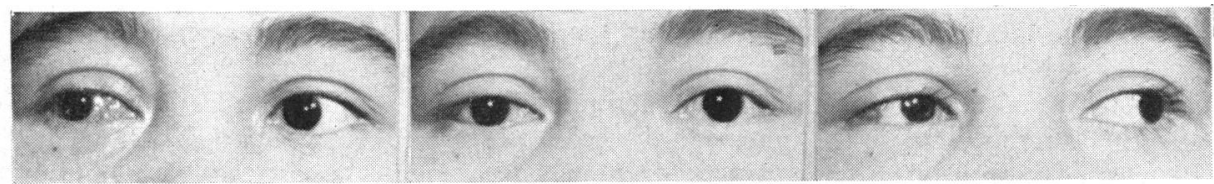

Fig. 6

FIG. 7

Fig. 8

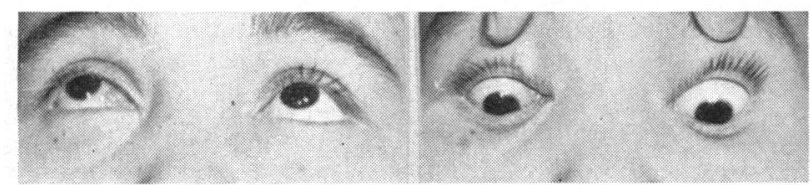

FIG. 9

Fig. 10

Figs 6-10.-Appearance 48 days after operation, in different positions of the gaze.

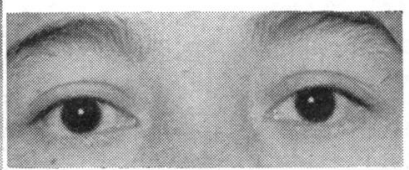

Fig. 11.-Appearance $9 \frac{1}{2}$ months after operation, looking straight ahead.

Contrary to the statement of Bielschowsky (1939), the position of the head was quite normal. At the site of the transplantation there was still a medium-sized reddish pimple. On looking to the extreme left there was some divergent deviation and diplopia; in all other directions there was no diplopia.

\section{Summary}

A case is reported of muscle-transplantation in a patient in whom the right medial rectus muscle was completely severed by trauma. Two hours after the operation adduction was possible, and after 48 days the patient's condition was satisfactory. The position of the head was normal, but there was some divergent deviation on looking to the extreme left.

\section{REFERENCES}

Bielschowsky, A. (1939). Amer. J. Ophthal., 22, 723 (cited by Gifford, 1940).

DUKE-ELDER, S. (1949). "Text-book of Ophthalmology", vol. 4, p. 3933. Kimpton, London. GifFORD, S. R. (1940). Arch. Ophthal. (Chicago), 24, 916.

MARINA, A. (1912). D Dtsch. Z. Nervenheilk., 44, 138.

(1915). Neurol. Zbl., 34, 338 (cited by Duke-Elder, 1949). 